AperTO - Archivio Istituzionale Open Access dell'Università di Torino

Morphology and structure of TixOynanoparticles generated by femtosecond laser ablation in water

This is a pre print version of the following article:

Original Citation:

Availability:

This version is available http://hdl.handle.net/2318/1669376

since 2018-06-05T12:28:17Z

Published version:

DOI:10.1088/2053-1591/aaba56

Terms of use:

Open Access

Anyone can freely access the full text of works made available as "Open Access". Works made available under a Creative Commons license can be used according to the terms and conditions of said license. Use of all other works requires consent of the right holder (author or publisher) if not exempted from copyright protection by the applicable law. 


\title{
MORPHOLOGY AND STRUCTURE OF Ti $_{x} O_{y}$ NANOPARTICLES GENERATED BY FEMTOSECOND LASER ABLATION IN WATER
}

\author{
J. Doneliene ${ }^{a}$, M. Rudzikas ${ }^{a}$, S. Rades ${ }^{b}$, I. Dörfel $^{b}$, B. Peplinski $^{b}$, M. Sahre ${ }^{b}$, F. Pellegrino $^{c}$, V. Maurino ${ }^{c}$, \\ J. Ulbikas ${ }^{a}$, A. Galdikas ${ }^{d}$, V.-D. Hodoroaba ${ }^{b}$ \\ "UAB "Modern E-Technologies", Vismaliuku str. 34, Vilnius LT-10243, Lithuania \\ ${ }^{b}$ Federal Institute for Materials Research and Testing (BAM), Unter den Eichen 87, 12205 Berlin, Germany \\ ${ }^{c}$ Dipartimento di Chimica e Centro Interdipartimentale NIS, Università di Torino, Via Pietro Giuria 5, 10125 \\ Torino, Italy \\ ${ }^{\mathrm{d}}$ Applied Research Institute for Prospective Technologies, Vismaliukų st. 34, LT-10243 Vilnius, Lithuania
}

\begin{abstract}
In this work pulsed laser ablation in liquid (PLAL) procedures for $\mathrm{TiO}_{2}$ anatase/rutile nanoparticle (NP) generation are reported. Ablation time was varied for optimization and time resolved investigation of NP generation processes. Morphology (size and shape), structure and concentration of resulting $\mathrm{TiO}_{2} \mathrm{NPs}$ were investigated by electron microscopy (SEM, TSEM and HR-TEM) and XRD in dependence on generation rate with link to particle properties.
\end{abstract}

\section{Keywords}

Laser ablation, $\mathrm{TiO}_{2}$ nanoparticles, characterization, HR-TEM, IPC-MS

\section{Introduction}

Titania $\left(\mathrm{TiO}_{2}\right)$ nanoparticles are a harmless, cheap, facile, bio-compatible, chemically and mechanically stable and highly efficient photo-catalyst [1] [2]. Physico-chemical properties of the titanium oxides allow their usage as photoanodes in dye-sensitized solar cells DSSC) and as photo-catalysts for selective synthesis of chemical compounds, for removal of environmental pollution and sterilization (viruses, bacteria and cancer cells), as well as the preparation of self-cleaning surfaces, gas sensors, biocompatible films covering medical implants, or simple antireflective layers [1, 3-4]. Various crystalline phases (among them rutile, brookite, or anatase) $[1,5]$ with controlled size, particle shapes, phase fraction and some other properties can be formed depending on the Ti precursors, as well as the synthesis technique, i.e. sol-gel $[6,7]$ method, hydrothermal [8] and/or solvothermal synthesis [1], polyol method [5] or solhydrothermal method [9]. Commonly used titanium sources in the synthesis of titania are $\mathrm{TiCl}_{3}, \mathrm{TiCl}_{4}$, $\mathrm{Ti}\left(\mathrm{SO}_{4}\right)_{2}$, titanium alkoxide, and titanium complexes
[10]. The main problem of these preparation methods is that the use of toxic solvents such as $\mathrm{HCl}$ (aq.), $\mathrm{H}_{2} \mathrm{SO}_{4}$ (aq.) and organic solvents is required $[1,5,7-9,10]$. Consequently, for making $\mathrm{TiO}_{2}$ preparation environment-friendly water should be used as a main liquid [10]. Titanium oxide nanoparticles preparation in liquid is a promising technique as it can be applied with low risk, and for the compatibility with other fabrication techniques (spraying [11], dip or spin coating [12-14], membranes of polymeric nanocomposites preparation [15-17]).

Another titania preparation method - pulsed laser ablation in liquids (PLAL) - is one of the most promising techniques for the synthesis of nanoparticles in liquids or in polymeric matrices [1822]. The PLAL method is compatible with the environment due to the fact that a metallic titanium plate and water are used as a titanium source and "green" solvent, respectively [18-21]. The formation of the mentioned oxides with certain structural and physical properties is mainly affected by the laser type (milli-/nano-/pico-/femto-second) and preparation conditions (frequency, pulse energy, duration of ablation, etc.) [18, 22-25]. Some authors assume that the usage of femtosecond lasers can effectively control the nanoparticle size in comparison to nanosecond laser ablation, and minimizes laser-plume interaction as well as reduces the heat affected zones [19, 26].

The production rate we achieved in the present study coincides with the data presented in the literature. Abubaker Hamad, Lin Li and Zhu Liu [27] analyzed $\mathrm{TiO}_{2}$ NPs made by 3 different types of lasers: nanosecond, picosecond and femtosecond. Resulting average production rates are similar for all of LA procedures used and are in the range of 0.05 - 
$0.07 \mathrm{mg} \mathrm{min}{ }^{-1}$, in spite of relatively high difference in ablation conditions. M. Zimbone et al. in work [4] used a very low frequency nanosecond laser ablation with high laser pulse energy and obtained rates from 0.03 to $0.07 \mathrm{mg} \mathrm{min}{ }^{-1}$. A. V. Simakin et al. [28] ablated $\mathrm{Ag}$ and $\mathrm{Au}$ metals with rates of about $0.01 \mathrm{mg} \mathrm{min}^{-1}$ for Ag NPs and $0.02 \mathrm{mg} \mathrm{min}^{-1}$ for $\mathrm{Au}$ NPs. Similar values were obtained by A. Schwenke et al. [29], i.e. $0.04 \mathrm{mg} \mathrm{min}^{-1}$ for $\mathrm{Mg}, 0.05 \mathrm{mg} \mathrm{min}^{-1}$ for $\mathrm{Zn}$ after $30 \mathrm{~min}$ of irradiation with picosecond laser.

Application of titania NPs even for laboratory purposes usually presumes at least $1 \mathrm{mg}$ of dry NPs powders. Such quantity may be obtained during $15-$ $30 \mathrm{~min}$ of LA process at production rates mentioned above. Natural way to get more NPs seems to be prolongation of LA procedure. However, laser beam interacts not only with the surface of metal plate but also with already generated NPs what means possibility of changes of the parameters of NPs with ablation duration. It has been demonstrated in [19] that size of NPs is reduced at second stage of LA procedure when metal plate is removed and laser beam hits already existing NPs. However, influence of ablation process duration on concentration and features of Ti NPs generated during usual PLAL procedure (metal plate immersed in liquid) has not yet been investigated.

The aim of this work is to investigate exact morphology, structure, shape and concentration of titania NPs obtained by PLAL procedure of various durations.

\section{Materials and methods}

\section{Materials and preparation}

In this work, a solid Ti plate $(99.99 \%$, Alfa Aesar $\mathrm{GmbH} \& \mathrm{Co} \mathrm{KG}$, Germany) with dimensions (25 x $25 \times 0.5) \mathrm{mm}$ was used. Distillated water (DI water) was employed as the ambient liquid in experiments. Acetone (99.8\%, Merck KGaA, Germany), ethanol (99.9\%, Merck KGaA, Germany), $\mathrm{HCl}$ (37\%, Sigma Aldrich, Germany) were all of analytical grade quality.

Before the experiments targets were polished, cleaned out with precision tissue wiper which was moistened in ethanol and washed ultrasonically in acetone $(5-10 \mathrm{~min}$.) followed by ultrasonic cleaning in ethanol (5-10 min.). Then the Ti plate was placed in an open heat-resistant glass container for direct laser access and filled with distilled water for $\mathrm{TiO}_{2}$ NPs preparation and accumulation of generated NPs.

Experiments for the synthesis of titania colloidal solutions for laser ablation in distilled water were performed using a $\mathrm{Yb}: \mathrm{KGW}$ (PHAROS by Light conversion,) femtosecond laser, operating at second harmonic $(513 \mathrm{~nm})$ with a $260 \mathrm{fs}$ pulse duration (Fig. 1). Beam repetition rate was $300 \mathrm{kHz}$ with fluence at the target surface of $4.78 \mathrm{~J} \mathrm{~cm}^{-2}$. The laser system was controlled by a computer with special software. The laser beam was continuously moved via scanning galvanometer automatically with a constant speed $\left(330 \mathrm{~mm} \mathrm{~s}^{-1}\right)$ across metal plate in rows of a rectangular serpentine pattern in a time range from $10 \mathrm{~min}$ to $90 \mathrm{~min}$. The resulting solutions with generated NPs were poured into clean containers and used for further analyses.

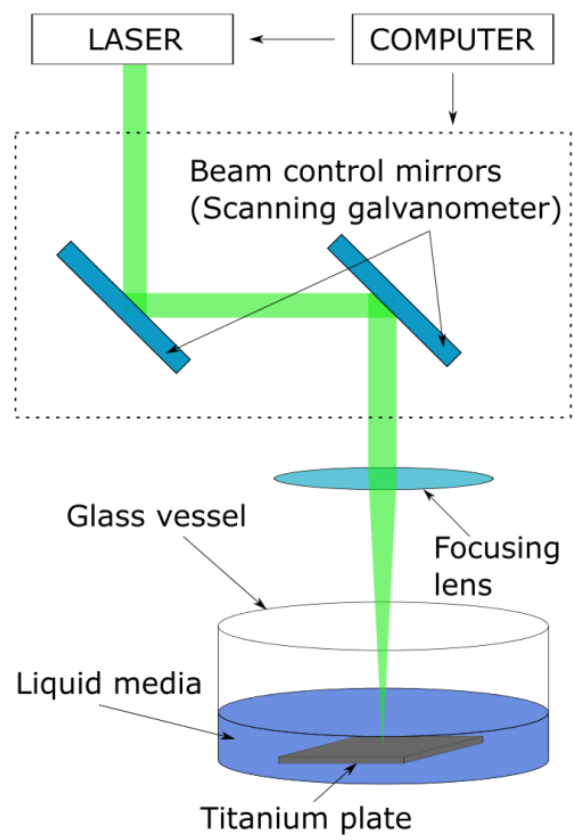

Fig.1. Experimental set-up of laser ablation in liquid media. Methods

The size, morphology and structure of NPs produced by LA were investigated via scanning electron microscopy (SEM), transmission scanning electron microscopy (TSEM) and scanning transmission electron microscopy (STEM), including high resolution transmission electron microscopy (HR-TEM). SEM measurements have been performed with a Zeiss Supra 40 (Carl Zeiss, Germany). The SEM instrument used in this work 
can be operated in transmission mode (T-SEM), which is enabled by employing a special transmission setup described in detail elsewhere [30]. The advantages of each detection mode can be exploited successfully for comprehensive analysis of nanoparticles [31,32]. The TEM investigations were performed using a STEM JEM 2200FS (JEOL, Japan), operated at $200 \mathrm{kV}$ acceleration voltage. It is equipped with an in-column energy filter, a scanning unit with bright field and High Angle Annular Dark Field (HAADF) detectors, and an EDX-system.

Specimens were prepared by depositing a drop either on a carbon coated copper TEM grid or Lacey carbon coated copper TEM grid, and absorbing excess liquid with laboratory tissue after a few minutes.

Energy dispersive X-ray spectroscopy (EDX) was used randomly to verify the elemental composition of the NPs??? The analysis of phases present in the generated $\mathrm{TiO}_{2}$ NPs was carried out by X-ray diffraction (XRD) applied in two versions on two different instruments, i.e. in the Bragg-Brentano geometry and with grazing incidence. XRD measurements in Bragg-Brentano geometry were performed with a Bruker-AXS D5000 diffractometer at room temperature using copper $K \alpha_{1,2}$ radiation, an $1.0 \mathrm{~mm}$ aperture, a $0.1 \mathrm{~mm}$ receiving slit, a sample spinner $(0$ or $15 \mathrm{rpm})$ and a scintillation counter. A corundum plate (NIST SRM 1976) was used to check and monitor the performance of the instrument. The sealed X-ray tube was operated at $30 \mathrm{kV}$ and $40 \mathrm{~mA}$.

The specimen of sample generated by $90 \mathrm{~min}$ of laser ablation was prepared by dispersing $0.4 \mathrm{ml}$ of the liquid suspension (total available amount $0.8 \mathrm{ml}$ ) on the polished and clean surface of a flat low background specimen holder (off-cut Si-wafer, $\varnothing 50 \mathrm{~mm})$ and consecutive drying in a dry-box at $46^{\circ} \mathrm{C}$ for $30 \mathrm{~min}$. This procedure was repeated once and led in the end to a specimen with a net dry weight of $0.7 \mathrm{mg}$ titanium oxide spread uniformly in a ca. $0.6 \mu \mathrm{m}$ thick layer over an area of approximately $18 \mathrm{~mm} \times 18 \mathrm{~mm}$. For comparison only, a reference specimen was prepared by putting $35 \mathrm{mg}$ of a well-defined nanocrystalline anatase powder (label UT_02-16) on top of the low background sample holder.

Diffraction data of the empty low background sample holder and of the specimen of sample " 90 - min", were collected from $5^{\circ}$ to $80^{\circ}$ in steps of $0.04^{\circ}$ for $10 \mathrm{~s}$ per step in each run. The total data accumulation time was increased to $320 \mathrm{~s}$ per step by repeating the measurement of the complete $2 \theta$-range 32 times and - after checking the individual diffraction curves for consistency - adding them up. In addition, a diffraction pattern of the above described reference specimen was collected using the same instrumental conditions but a much shorter total data accumulation time of just 5 s per step. In this diffraction pattern the (101) anatase reflection peak at about $25.3^{\circ}$ is characterized by a very satisfactory value of about 36 for both the signal-tobackground ratio and the signal-to-noise ratio.

Grazing Incidence XRD diffractograms were measured with a XRD 3000 TT (Seifert), operating at $40 \mathrm{kV}, \quad 40 \mathrm{~mA}$, using secondary HOPG monochromator filtered $\mathrm{Cu}-\mathrm{K}_{\alpha}$ radiation in a parallel beam configuration, at a grazing incidence of $\Omega=$ $1.3^{\circ}$ and with steps of $0.08^{\circ} 2 \theta$ and $0.2^{\circ} 2 \theta$.

The specimens of samples " $20 \mathrm{~min}$ " and " $90 \mathrm{~min}$ " were prepared by depositing each of the suspension on the cleaned surface of a Si wafer with (100) orientation as specimen holder and subsequent drying in air. This procedure was repeated three times. After that, a specimen with a net dry weight of less than $1 \mathrm{mg}$ titanium oxide distributed over an area of approximately $10 \mathrm{~mm} \quad \mathrm{x} \quad 20 \mathrm{~mm}$ was obtained.

ICP MS has been used to determine concentration of NPs. Assumption has been made that all titanium in suspension is oxidized and $\mathrm{Ti}_{\mathrm{x}} \mathrm{O}_{\mathrm{y}}$ compounds are background of NPs, so amount of Ti ions is proportional to concentration of NPs. In order to evaluate the total amount of Ti ions in the samples, a complete mineralization in microwave was carried out. $1 \mathrm{ml}$ of sample was diluted with $9 \mathrm{ml}$ of $\mathrm{HCl}$ $(37 \%)$ in a $100 \mathrm{ml}$ TFM vessel and then treated using the following protocol:

- 20 minutes ramp from $\mathrm{T}$ ambient to $200^{\circ} \mathrm{C}$;

- $15 \mathrm{~min}$ at $200^{\circ} \mathrm{C}$ under vigorous stirring;

- Slow cooling in air from $200^{\circ} \mathrm{C}$ to ambient T;

The obtained clear solution was diluted to a final volume of $25 \mathrm{ml}$ (to recover quantitatively the sample) before taking $1 \mathrm{ml}$ of that solution and diluting it with $9 \mathrm{ml}$ of $1 \%$ standard nitric acid.

The final solution was the analyzed with an ICP- 
MS apparatus in order to quantify the Ti ions. ICPMS analyses were carried out using a Thermoscientific ICP-MS ICAP-Qs model, equipped with a quadrupole mass analyzer and a flatpole quadrupole collision / reaction cell. The instrument is calibrated with $1 \%$ standard nitric acid standard for $\mathrm{Ti}$ ions prepared by diluting standard reference certificates at $1000 \mathrm{mg} \mathrm{L}^{-1}$ using ${ }^{45} \mathrm{Sc},{ }^{89} \mathrm{Y},{ }^{159} \mathrm{~Tb}(100$ $\mathrm{ppb})$ as internal standards. The calibration curve was constructed with 5 points and linear correlation coefficient $>0.99$. Interference due to polyatomic ions is eliminated by operating the collision cell in He mode with kinetic energy discrimination ( $\mathrm{He}-$ KED). ${ }^{48} \mathrm{Ti}$ was used for quantitation.

Other parameters as follows:

- RF power: $1450 \mathrm{~W}$

- Main Ar Flow: $15 \mathrm{~L} \mathrm{~min}^{-1}$

- Ar auxiliary flow: $1.0 \mathrm{~L} \mathrm{~min}^{-1}$

- Nebulizer flow: $0.90 \mathrm{~L} \mathrm{~min}^{-1}$

- Concentric nebulizer with impact sphere

- Collision cell He flow: $5.0 \mathrm{~mL} \mathrm{~min}^{-1}$

- Extraction Lens voltages and KED bias: autooptimized with the tuning solution suggested by the vendor.

\section{Results and discussion}

Fig. 2 shows dependence of $\mathrm{Ti}$ concentration which we believe is proportional to concentration of NPs obtained by ICP MS on duration of LA procedure. NPs concentration increases with

increasing duration of ablation with a linear dependence on ablation duration. NPs production rate calculated from linear approximation $\left(R^{2}=0.9461\right)$ of concentration curve equals about

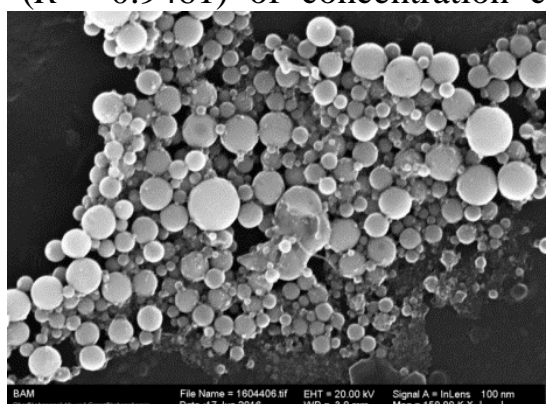

a
$0.07 \mathrm{mg} \mathrm{min}^{-1}\left(4.2 \mathrm{mg} \mathrm{h}^{-1}\right)$ what is in accordance with results of other authors [4,27].

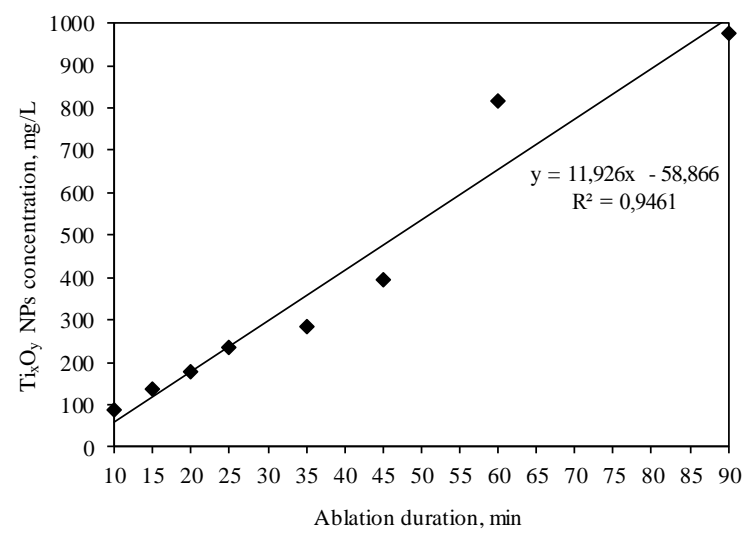

Fig. 2. $\mathrm{TiO}_{2} \mathrm{NPs}$ concentration change after different duration $(\mathrm{t}=10 ; 15 ; 20 ; 25 ; 35 ; 45 ; 60 ; 90 \mathrm{~min}$. $)$ of $1^{\text {st }}$ stage LA.

Rate of ablation does not reach saturation, what could be expected because of laser beam interaction with already generated NP ("second stage of ablation") instead of Ti plate [19]. Simple evaluation shows that under experiment conditions even at longest ablation duration the number of photons is much higher than number of generated NPs. Therefore, most of the photons reach Ti plate and generate new NPs and so ensure linear dependence of concentration on ablation duration.

SEM/TEM measurement results are shown in Fig. 3. Notable feature of NPs is their spherical shape with diameter $10-150 \mathrm{~nm}$ what is in agreement with [ ].

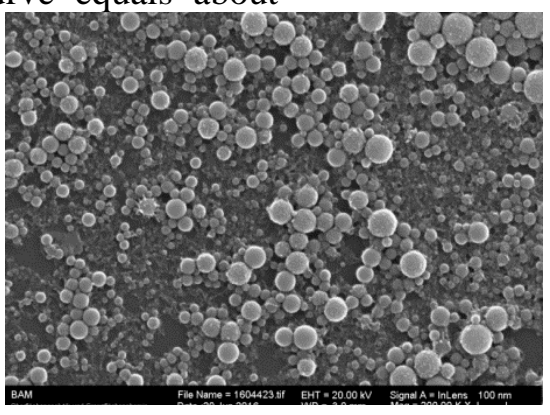

$\mathrm{b}$

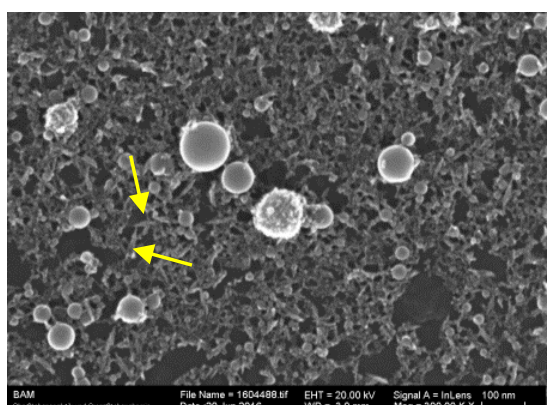

$\mathrm{c}$ 


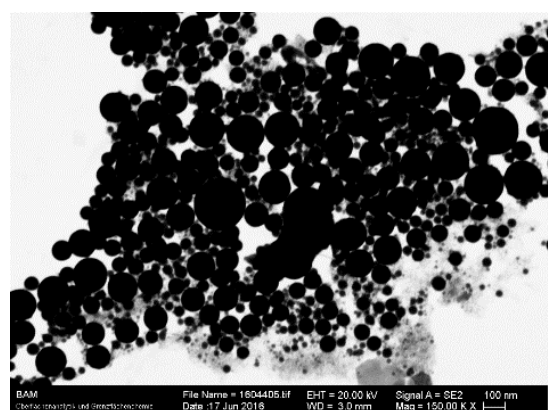

$\mathrm{d}$

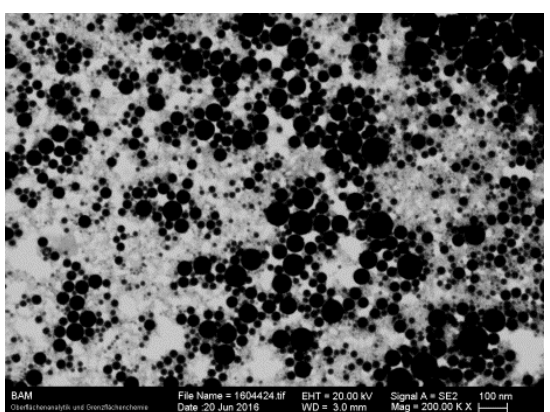

e

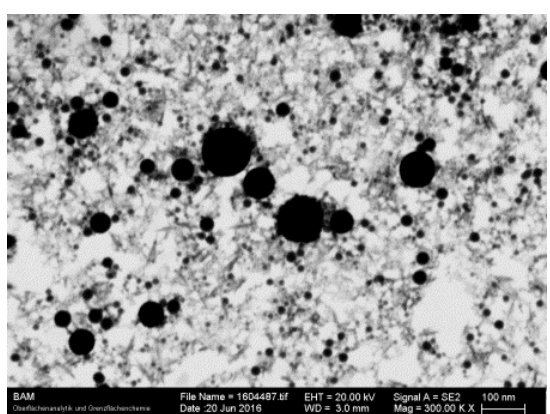

$\mathrm{f}$

Fig. 3. SEM (a, b, c) and T-SEM (d, e, f) micrographs of $\mathrm{TiO}_{2} \mathrm{NPs}$ produced via LA of Ti plate in DI water at different LA duration: a, $d-10$ min., b, e- 20 min., c, f -90 min.

T-SEM analysis has been performed on eight samples (corresponding to an ablation time between 10 and $90 \mathrm{~min}$ ) in order to reveal exact size of round particles [30, 31]. For that, diameters of several hundred up to 2000 nearly spherical particles have been traced manually in the T-SEM images. Minor number of particles with rod-like appearance which are present in the 90-min-sample as described above have not been included for this analysis to maintain comparability between samples. T-SEM image resolution of about $10 \mathrm{~nm}$ causes that NPs with sizes below $10 \mathrm{~nm}$ are not able to be analyzed. Fig. 4 illustrates the particle size distributions of all eight NPs samples corresponding to different ablation periods as extracted from T-SEM data. All distribution profiles exhibit a relative polydispersity of particulates. Occasionally, larger particles have been measured, but are not shown in Fig. 4 for better visibility of the graphs. By comparing statistical values of the particle size distributions, see Table 1 , it can be observed that tendentially particle size decreases with longer ablation times.

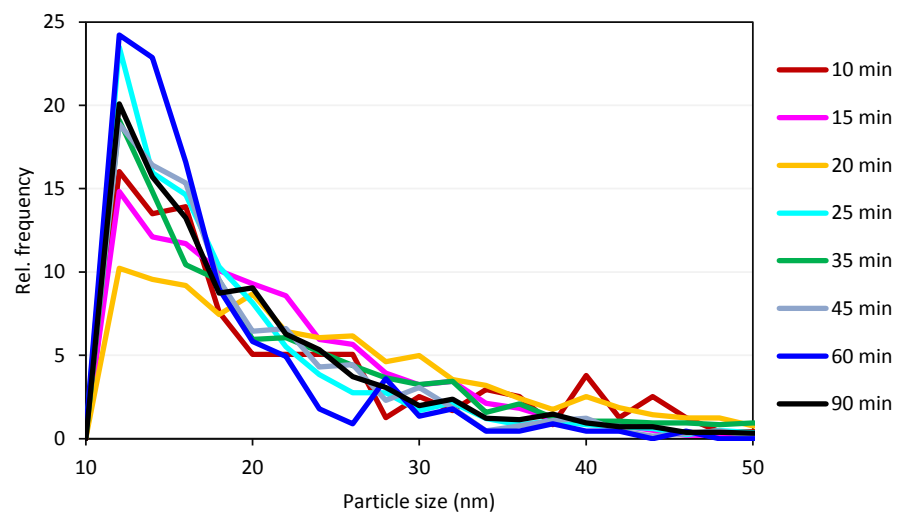

Fig. 4. Extracts of size distributions (bin of 2) of titanium oxide NPs produced by femtosecond laser treatment of a Ti plate. Ablation duration: $10 \mathrm{~min}, 15 \mathrm{~min}, 20 \mathrm{~min}, 25 \mathrm{~min}, 35 \mathrm{~min}, 45 \mathrm{~min}, 60 \mathrm{~min}$ and $90 \mathrm{~min}$.

By comparing statistical values of the particle size distributions, see Table 1, it can be observed that tendentially round particles diameters decrease with longer ablation times. The observation that at longer ablation times NPs with rather smaller diameters are generated could be attributed to interaction of laser light with already produced NPs.

Table 1. Characteristics of extracts of particle size distributions.

\begin{tabular}{|l|c|c|c|c|c|c|c|c|}
\hline Duration of laser ablation & $10 \mathrm{~min}$ & $15 \mathrm{~min}$ & $20 \mathrm{~min}$ & $25 \mathrm{~min}$ & $35 \mathrm{~min}$ & $45 \mathrm{~min}$ & $60 \mathrm{~min}$ & $90 \mathrm{~min}$ \\
\hline Number of analyzed particles & 237 & 991 & 1947 & 834 & 958 & 652 & 223 & 2121 \\
\hline Mode (nm) & 17 & 11 & 21 & 12 & 11 & 15 & 14 & 11 \\
\hline
\end{tabular}




\begin{tabular}{|l|c|c|c|c|c|c|c|c|}
\hline Median (nm) & 18 & 18 & 22 & 15 & 17 & 16 & 14 & 16 \\
\hline Mean size (nm) & 25 & 22 & 26 & 19 & 21 & 21 & 18 & 20 \\
\hline Standard deviation (nm) & 19 & 16 & 15 & 11 & 12 & 15 & 16 & 15 \\
\hline Minimum size (nm) (defined cut-off) & 10 & 10 & 10 & 10 & 10 & 10 & 10 & 10 \\
\hline Maximum size (nm) & 178 & 146 & 110 & 122 & 91 & 127 & 197 & 241 \\
\hline
\end{tabular}

Some kind of "matrix material" appears at longer durations (more than $20 \mathrm{~min}$ ) in which spherical NPs are embedded. A change in matrix amount is notable at longer ablation durations (almost stepwise between 20 and $25 \mathrm{~min}$ samples). It contains particles that resemble of rod-like shape (Fig. 3c, yellow arrows) NP network. TEM pictures (Fig. $3 \mathrm{~d}$, e, f) allow a clearer distinction of particle types described above. To elucidate the origin of matrix material second stage LA experiments have been performed. As the first step, usual LA procedure of 20 min. duration was carried out $\left(1^{\text {st }}\right.$ stage of ablation). After that, $\mathrm{Ti}$ plate was removed and solution with produced NPs is re-irradiated under the same laser parameters at 25, 90, 180 and 270 min. $\left(2^{\text {nd }}\right.$ stage $)$. This leads to reduction of the size of round NPs and to appearance of "matrix material" (Fig. 5) similar to that obtained during $1^{\text {st }}$ stage LA at longer ablation durations (Fig. 3). However, origin of "matrix material" generated during $1^{\text {st }}$ stage can't be attributed only to the interaction of laser light with already produced spherical NPs. As it was mentioned earlier, during $1^{\text {st }}$ stage LA the biggest part of nanomaterial is generated by huge number of photons hitting Ti plate. Under our experimental conditions, laser beam travels many times by the same serpentine path during ablation procedure generating NPs and so damaging $\mathrm{Ti}$ surface. Therefore, we can assume that "matrix material" is generated by interaction of photons with already generated NPs and with damaged Ti plate surface as well.

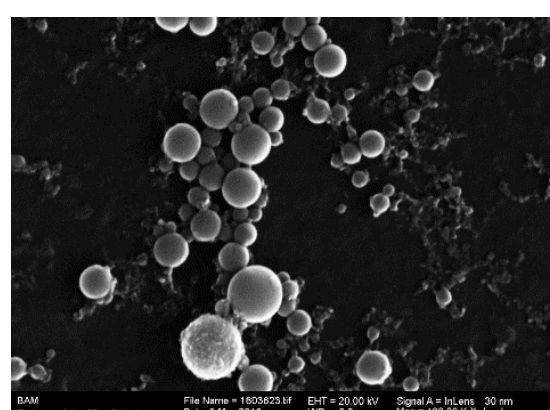

a

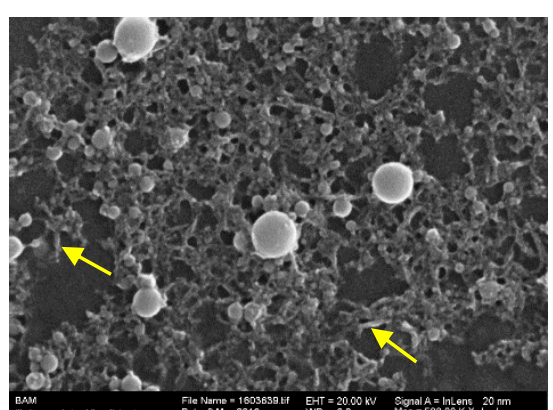

$\mathrm{b}$

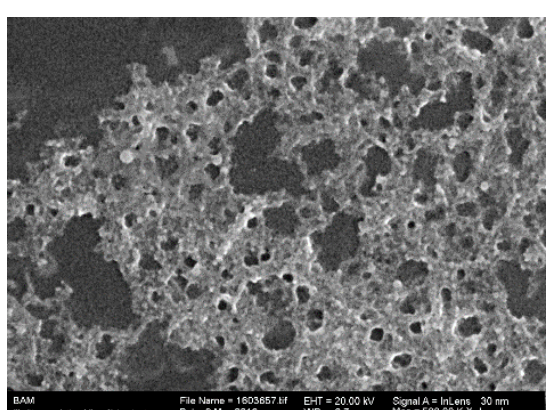

c

Fig. 5. SEM micrographs of $\mathrm{TiO}_{2} \mathrm{NPs}$ produced via $2^{\text {nd }}$ stage of LA of Ti plate in DI water at different LA duration: a -25 min., $\mathrm{b}-$ 90 min., c - 270 min. Rod shape NPs are indicated by yellow arrows are alike to those in Fig. 3 .

Samples obtained during 20 and 90 min ablation duration procedure have been selected from all sample series for further investigation. Selection was made because of maintaining the highest difference in duration and acceptable NPs concentration for reliability of the results as well as combining it with visual inspection.

Both two samples have been analyzed with respect to their phases with XRD. Two different instrumental geometries, namely Bragg-Brentano and grazing incidence were used. For this, sample dispersion was dropped and dried on a single crystal Si wafer. Diffractograms of both samples (Fig. 6) reveal only a small number of reflections, which are broadened and of poor signal-to-background ratio as compared to the diffraction pattern of the (reference) nanocrystalline $\mathrm{TiO}_{2}$ powder. The latter was measured as reference sample under the same measurement conditions. A major contribution to this line broadening is caused by the very small size of the nano-crystals, which has been confirmed by 
T-SEM and SEM (Fig. 3). However, it cannot be ruled out that other factors contribute as well to this broadening. Among them are microstrain caused by deviations from stoichiometry as well as partial overlap of nearly coinciding neighboring lines, belonging to different nanocrystalline components. Low intensities of reflections could be ascribed to the really low amount of sample material available for analysis (less than $1 \mathrm{mg}$ on the sample holder) as well as to the low percentage of nanocrystalline component(s) in the mainly X-ray amorphous sample. The named factors: low net intensities and broadening of reflections result in the low number of observed diffraction lines. This, together with the presumably poor crystallite orientation statistics, hinders unambiguous crystalline phase identification.

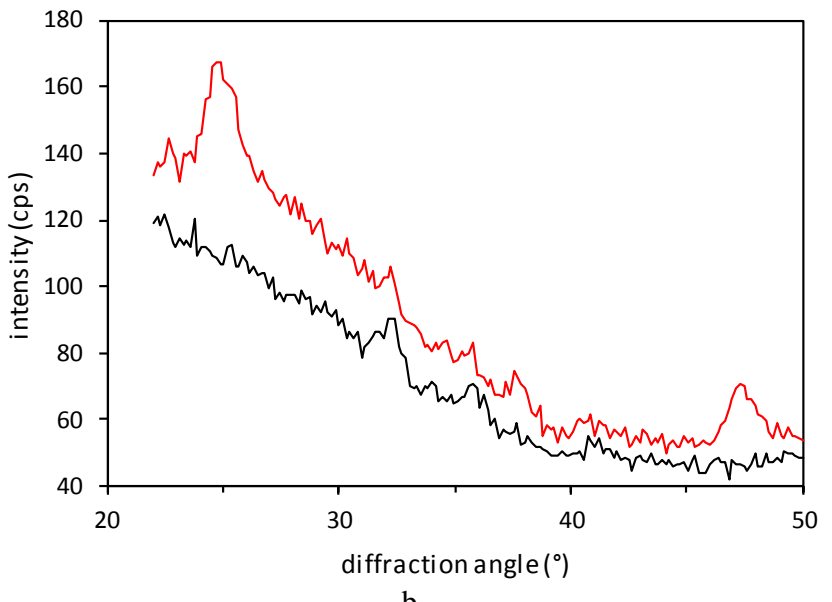

Fig. 6, a: section of the diffraction patterns of the 90-min-sample (upper, red curve) and the empty sample holder (lower, blue curve) collected in Bragg-Brentano geometry. The inset demonstrates that both curves converge at small and large diffraction angles. b: diffraction pattern acquired in grazing incidence geometry of the 90-min-sample (upper, red curve) and of the 20-min-sample (lower, black curve).

The 90-min-sample was analyzed by X-Ray Powder Diffraction (XRD) using a diffractometer operated in the Bragg-Brentano geometry (Fig. 6a). The diffraction pattern resulting from this measurement together with the diffraction pattern of the empty sample holder measured under identical conditions are depicted in Fig. 6a, red and blue curves, respectively. From these two diffraction patterns it is obviously that the (by far) biggest percentage of net intensity scattered by the titanium oxide specimen contributes to the broad halo of diffuse scattering ranging from about $15^{\circ}$ to $50^{\circ}$ (all Bragg angles in 20). Only a much smaller percentage of net intensity is concentrated in a limited number of diffraction lines that prove the presence of a nanocrystalline fraction that apparently is made up by more than a single component. Diffractograms of both samples, but in dependence on the measurement geometry (Bragg-Brentano and grazing incidence), see Fig. 6, provide indications regarding crystalline phases of titanium oxide as described in the following.

The 90-min-sample shows two prominent reflections at about $25^{\circ}$ and $48^{\circ}$ and one less pronounced reflection at about $38^{\circ}$. All three reflections, which are considerably broadened, could be assigned to anatase (PDF [21-1272]), originating from reflections by the $\{101\},\{200\}$ and $\{004\}$ crystallographic planes, respectively. As the peak positions of one of the polymorphs of titania, brookite (PDF [29-1360]), are close to those of the anatase mentioned above, they could not be resolved due to the considerable broadening of the observed reflections and, moreover, the lower reflection intensity of each lattice plane due to the orthorhombic crystal structure of brookite (17 lowmiller-index Bragg reflections within analyzed angle range, compared to 5 for tetragonal anatase and rutile, and 3 to 4 for hexagonal titania phases). Hence, based on available diffractograms the presence of a minor fraction of brookite cannot be 
ruled out for the 90-min-sample. The same holds true for the Magnéli phase $\mathrm{Ti}_{3} \mathrm{O}_{5}$ (PDF [82-1137]). There are two additional reflections in the diffractogram present at about $32^{\circ}$ and $36^{\circ}$ and a signified one at about $41^{\circ}$, whereby the former could not be assigned to a $\mathrm{TiO}_{2}$ polymorph. However, this reflection at $32^{\circ}$ further suggests the presence of $\mathrm{Ti}_{3} \mathrm{O}_{5}$. The other two reflections could correspond to rutile (PDF [76-323]). On the other hand, the absence of the rutile (110) reflection is rather opposed to this assignment. It should be noted that the profile of the reflex at $25^{\circ}$ suggests more than one phase, which could be at about $24.9^{\circ}$ e.g. beta- $\mathrm{TiO}_{2}(\mathrm{PDF}$ [35-88]).

In comparison to the 90-min-sample the diffractogram of the 20-min-specimen, which has been obtained by measurement at grazing incidence angle, does contain reflections, too, even though their number is smaller compared to the number of the 90-min-sample, as can be seen in Fig. 6b. The reflections at $25^{\circ}, 38^{\circ}$ and $48^{\circ}$ are missing, but reflections at $32^{\circ}, 36^{\circ}$ and $41^{\circ}$ are present, which are similar to the ones of the 90-min-sample. Missing reflections in 20-min-sample are possibly of anatase phase and their appearance in 90-min-sample could be more than coincidence to rod-like shaped nanoparticle appearance. However the lack of reflections might be due to the lower concentration of sample dispersion as well. In fact, as it is described later in the TEM section, both samples analyzed with HR-TEM contain a substantial amount of particles in the amorphous state. Another possible reason for the low number of detected reflections, which prevents distinct phase identification could be due to a poor crystallite orientation statistics.

Further insights have been revealed by the HR-TEM measurements for morphology and structural nature of individual $\mathrm{Ti}_{\mathrm{x}} \mathrm{O}_{\mathrm{y}}$ NPs. Representative images are displayed in Fig.7. Particles are visible which are polydisperse in size and have a nearly spherical shape. However, some of them show buckled surface regions in contrast to the spherical particles with a rather smooth surface. This buckled appearance of a number of particles in each acquired image could be either a layer or an intrinsic part of the particles themselves.

Particles exhibit lattice planes as can be seen in Fig. 7a and $\mathrm{c}$ of the 20-min-sample. The whole particle, of which the outer region is shown in Fig. 7a exhibits lattice planes and is thus completely crystalline. On the other hand, an amorphous surface region of the particle in Fig. 7c is visible. A third type of particles is comletely amorphous (see Fig. 7e). It can be concluded that the 20-min-sample is a mixture of roughly three types of particles, namely (i) fully crystalline ones, (ii) partly crystalline ones and (iii) amorphous ones; hence, particles produced by $20 \mathrm{~min}$ of laser ablation possess different degrees of crystallinity. Furthermore, several polycrystalline NPs have been identified. The surfaces of crystalline particles, are not very compact, but rather frayed, and compared to e.g. those of titania NPs with bipyramidal shape $[33,34]$, no well-defined crystallographic facets have been formed as can be seen in Fig. $7 \mathrm{~g}$.

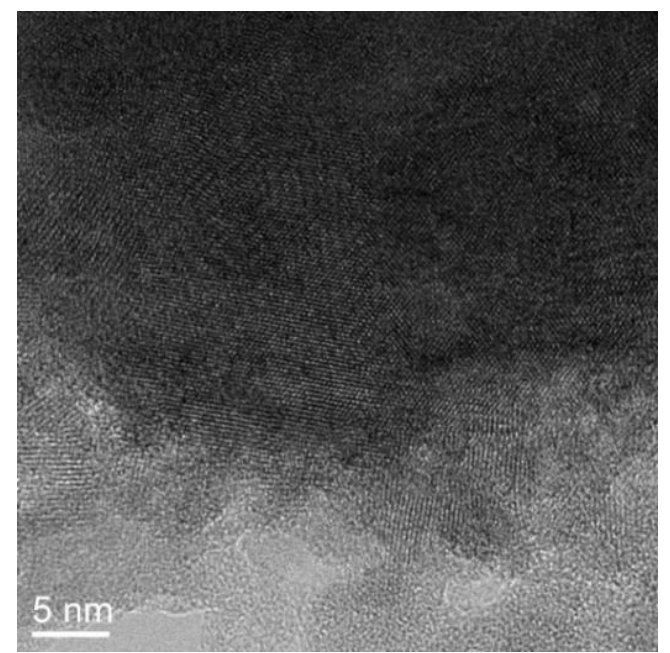


a

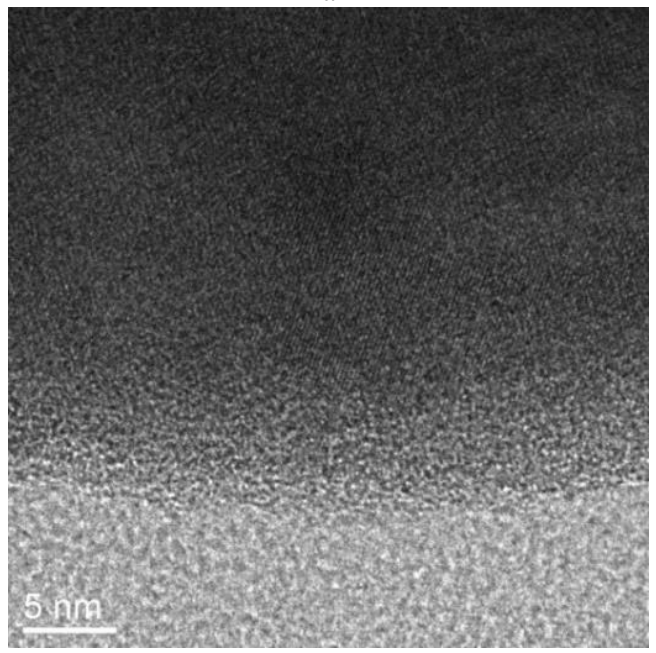

c

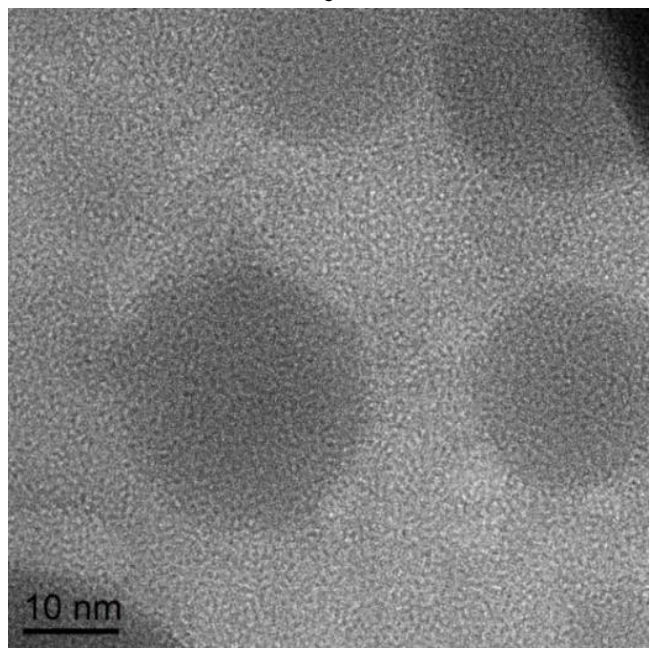

e

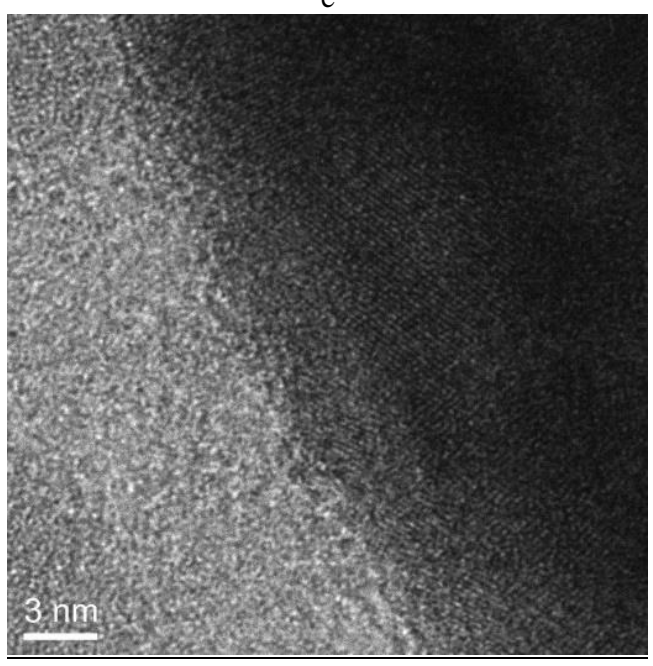

g

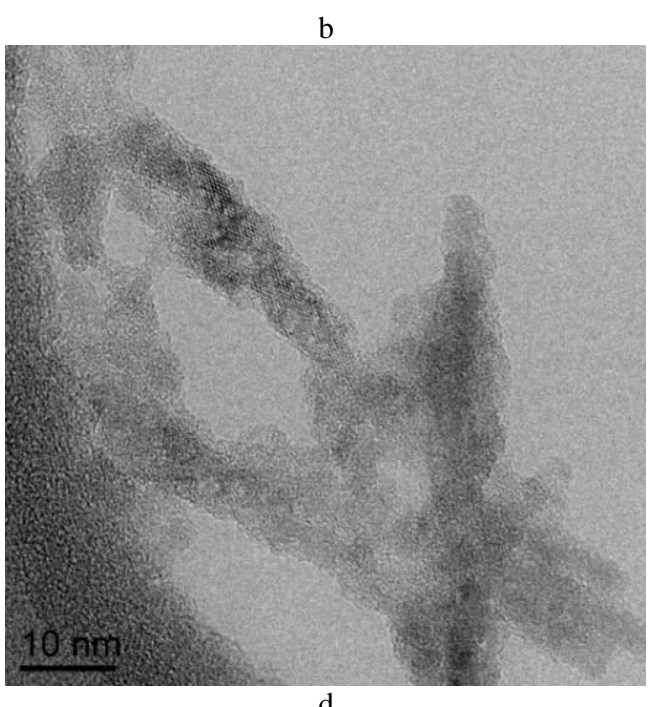

d

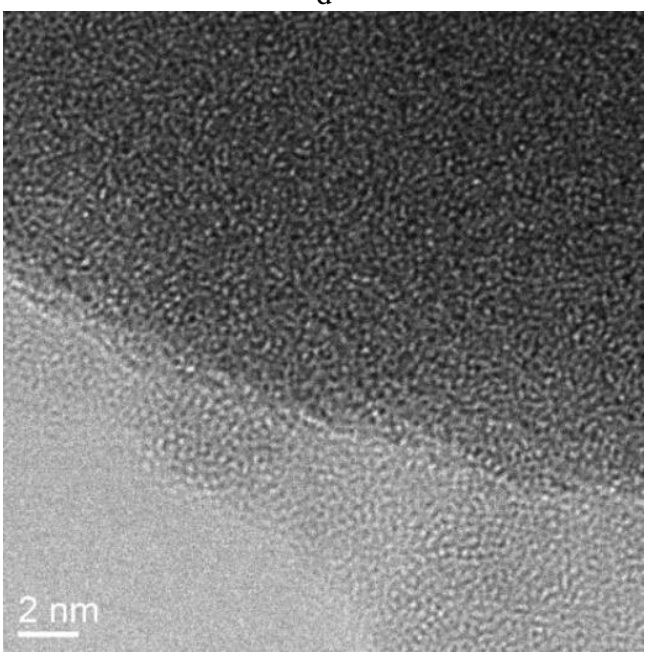

f

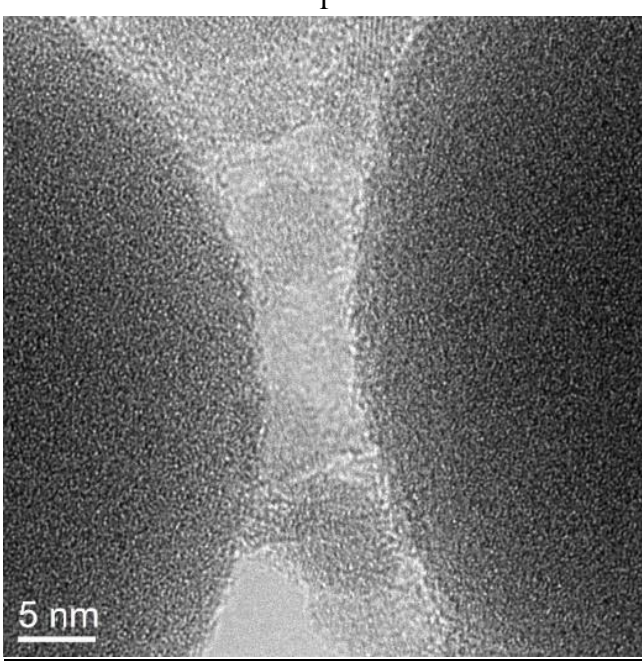

$\mathrm{h}$

Fig. 7. Bright-field HR-SEM and HR-TEM images of $\mathrm{TiO}_{2} \mathrm{NPs}$ after different duration of laser ablation: $\mathrm{t}=20 \mathrm{~min}(\mathrm{a}, \mathrm{c}, \mathrm{e}, \mathrm{g})$ and $\mathrm{t}=$ $90 \min (b, d, f, h)$. 
Via application of Fast Fourier Transformation (FFT) to selected HR-TEM images of nanoparticles $d$-spacings have been measured and are displayed in Table 2. A number of $d$-spacings matches with those of titanium(IV) oxide. Due to the broadness of the diffraction spots and the incomplete FFT patterns a clear discrimination between the $\mathrm{TiO}_{2}$ polymorphs rutile, anatase and brookite is rather difficult. A hint to the existence of the latter is given by the detection of a reflection at $0.29 \mathrm{~nm}$, fitting to (121) reflection of the brookite structure. This indication is rather vague because of the multitude of Ti-O-phases, containing reflections at $0.29 \mathrm{~nm}$. It was possible to index a FFT of one of the larger particles of the sample produced after 20 minutes of laser ablation.

Table 2. Measured $d$-spacings from FFTs of different particles in HR-TEM images of the sample with 20 min laser example is shown in Fig. XX) in comparison to those of titanium oxid phases from Joint Committee on Powder Diffraction standards (JCPDS). Miller indices of latice planes are shown in brackets.

\begin{tabular}{|c|c|c|c|c|c|}
\hline $\begin{array}{l}\text { Measured } \\
d(\mathrm{~nm})\end{array}$ & $\begin{array}{l}\text { Anatase, } \\
d_{\mathrm{hkl}}(\mathrm{nm})\end{array}$ & $\begin{array}{l}\text { Brookite, } \\
d_{\mathrm{hkl}}(\mathrm{nm})\end{array}$ & $\begin{array}{l}\text { Rutile, } \\
d_{\mathrm{hkl}}(\mathrm{nm})\end{array}$ & $\begin{array}{l}\beta-\mathrm{TiO}_{2}, \\
d_{\mathrm{hkl}}(\mathrm{nm})\end{array}$ & $\begin{array}{l}\mathrm{Ti}_{3} \mathrm{O}_{5}, \\
d_{\mathrm{hkl}}(\mathrm{nm})\end{array}$ \\
\hline 0.35 & $0.3520(101)$ & $0.3512(120)$ & & & \\
\hline 0.34 & & $0.3465(111)$ & & & $0.3376(002)$ \\
\hline 0.27 & & $0.2729(200)$ & & $\begin{array}{c}0.2697(310) \\
0.2687(-311)\end{array}$ & $0.2661(310)$ \\
\hline 0.24 & $0.2378(004)$ & $0.2409(201)$ & & $0.2381(401)$ & $\begin{array}{c}0.2465(-312) \\
0.2383(202)\end{array}$ \\
\hline 0.22 & & $0.2244(022)$ & 0.2188 (111) & $0.2249(112)$ & $\begin{array}{c}0.2240(121) \\
0.2237(-411)\end{array}$ \\
\hline 0.17 & $\begin{array}{l}0.1699(105) \\
0.1667(211)\end{array}$ & $\begin{array}{l}0.1691(320) \\
0.1662(241)\end{array}$ & $0.1687(211)$ & $\begin{array}{c}0.1729(113) \\
0.1715(601) \\
0.1693(-603)\end{array}$ & $\begin{array}{c}0.1759(510) \\
0.1737(222) \\
0.1722(420) \\
0.1671(-114)\end{array}$ \\
\hline 0.14 & $0.1364(116)$ & $\begin{array}{l}0.1434(213) \\
0.1417(161)\end{array}$ & $0.1424(221)$ & $\begin{array}{c}0.1427(-713) \\
0.1419(-223) \\
0.1392(023) \\
0.1379(-621)\end{array}$ & $\begin{array}{c}0.1451(-332) \\
0.1440,(204) \\
0.1410(-604) \\
0.1392(-424) \\
0.1389(512)\end{array}$ \\
\hline 0.12 & $\begin{array}{l}0.1189(008) \\
0.1173(303)\end{array}$ & $\begin{array}{l}0.1238(024) \\
0.1211(124) \\
0.1207(124)\end{array}$ & $0.1201(212)^{\mathrm{c}}$ & $0.1211(-424)$ & \\
\hline JCPDS card no. & [21-1272] & [29-1360] & [21-1276] & [46-1238] & [40-806] \\
\hline
\end{tabular}

This FFT fits well to anatase in $\left[\begin{array}{lll}-1 & -3 & 1\end{array}\right]-$ orientation, see Fig. 8. Noteworthily, intense diffraction spot of rutile structure with $d=$ $0.3247 \mathrm{~nm}$ which corresponds to (110) lattice planes did not appear in the FFTs. Other authors have also reported predominance of anatase and brookite phases in case of laser ablated nanoparticles, despite bulk rutile being the most stable form of $\mathrm{TiO}_{2}$ under ambient conditions [35,36]. Furthermore, Magnéli phase $\mathrm{Ti}_{3} \mathrm{O}_{5}$ or triclinic members of the homologous series $\mathrm{Ti}_{\mathrm{n}} \mathrm{O}_{2 \mathrm{n}-1}$ cannot be excluded, due to the correspondence of detected $d$-values with literature values and especially as the inter-planar distance of $0.27 \mathrm{~nm}$ indicates strong reflection of those phases. Moreover, only in some of the FFTs a reflection with a $d$ of $0.37 \mathrm{~nm}$ is present. This diffraction spot matches with (012) reflection of $\mathrm{Ti}_{2} \mathrm{O}_{3}$ as well as with (201) of beta- $\mathrm{TiO}_{2}$. It has to be mentioned that the TEM method is not integrative, it allows inferences about a number of random crystallites, only. 


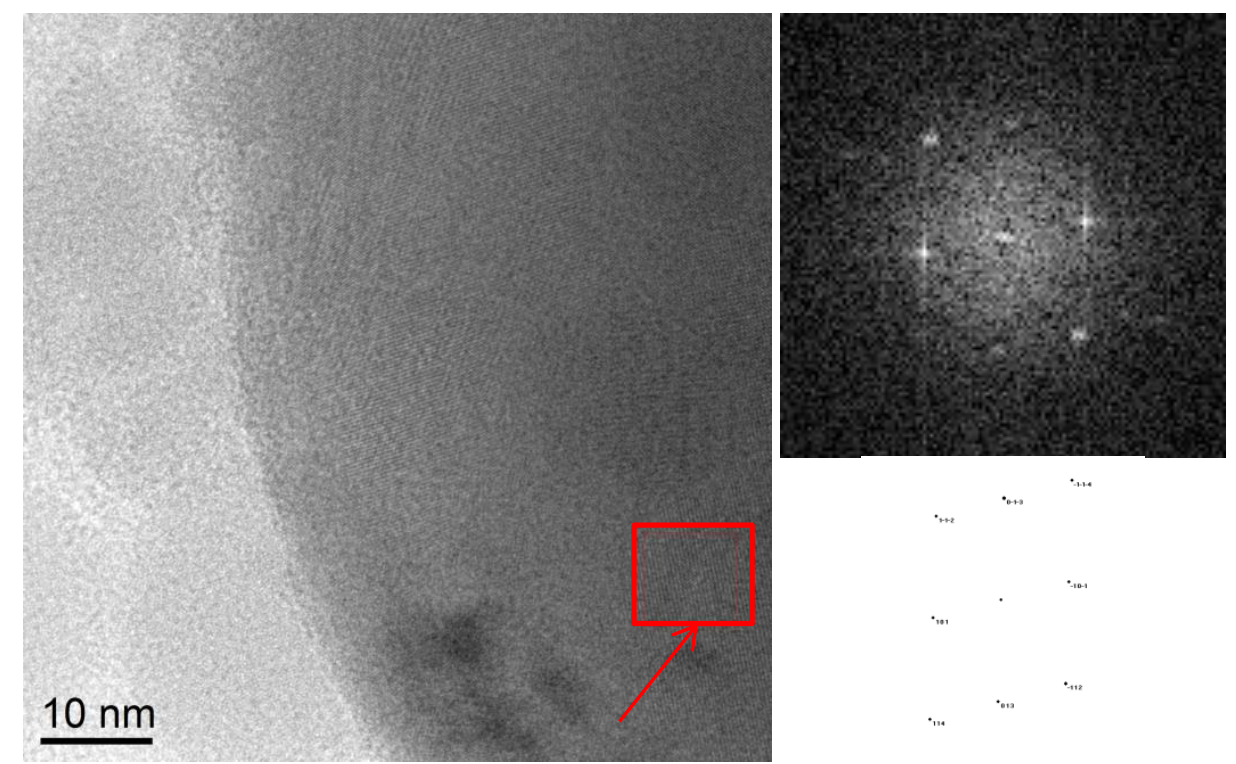

Fig. 8. left: Sample after 20 min of laser ablation, HR-TEM image of a big particle with visible lattice fringes and Moiré patterns. Small amorphous particles are attached. Right: FFT of the marked region of the crystalline particle with simulation, fitting to anatase in [-1 -3 1]-orientation.

Increasing the laser ablation time from $20 \mathrm{~min}$ to 90 min produces Ti-O - particles, which at first sight look similar to the particles obtained within $20 \mathrm{~min}$ of laser ablation as can be seen in the SEM image in Fig. 3c. Titania NPs synthesized by $90 \mathrm{~min}$ of laser ablation are relative broadly size distributed just as the NPs obtained within $20 \mathrm{~min}$. Also, surface morphology of nanoparticles varies from very smooth to rough and bumpy, respectively. Similarly, a change in NPs matrix is present for longer ablation durations (as mentioned before), where bigger, spherical particles are laid on or are embedded in. Smaller particles of more irregular shape and particles of elongated form were identified and could be assigned to this matrix. In contrast to short time laser ablation and by taking a closer look on the SEM image one can register this new appearance of very fine particles, which are of a rod-like shape (indicated by yellow arrows in Fig. 3c). TEM image in Fig. $7 \mathrm{~d}$ of such particles reveals their partial crystallinity by visible lattice planes. Regarding crystallinity, particles of a rather large size in the 90min-sample exhibit lattice planes shown in HR-TEM micrographs in Fig. $7 \mathrm{~b}$ and are of polycrystalline structure. This is indicated by the presence of different lattice planes within one particle and the clear distinction of smaller particles which are visible within a bigger one as well as the occurrence of Moiré patterns suggesting that the bigger NPs consist partly of former single smaller ones. The prolonged energy input of the laser might cause a selective-laser-sintering of particles forming larger ones, see Fig. 9 as an example. Sintering may involve recrystallization and coalescence. Furthermore, Ostwald ripening, at the expense of smaller particles, could have taken place in solution. The surface of (crystalline) bigger particles is very frayed, and there are no well-defined crystallographic facets.

FFTs calculated from HR-TEM images revealed broad diffration spots with various $d$-spacings suggesting different Ti-O -phases to be present after 90 min of laser ablation, which is identical for the sample after 20 min duration, as described above. However, (110) diffraction spot of rutile [JCPDS 211276] with an interplanar distance of $0.32 \mathrm{~nm}$ has been identified after prolonged time of laser treatment. This (110) spot has not been observed in the FFTs of the sample with much shorter laser ablation duration. In addition to the $\mathrm{TiO}_{2}$ phases present in the 90-min-sample, detected $d$-spacing of $0.45 \mathrm{~nm}$ could possibly be assigned to one ore more suboxides, e. g. (110) of $\mathrm{Ti}_{3} \mathrm{O}_{5}$ [JCPDS 40-806]. Short (20 min) as well as long (90 min) duration of femto-second laser ablation in water provokes $\mathrm{Ti}-\mathrm{O}-$ nanoparticles, which are not phase-pure. These 
results are in agreement with XRD findings described in section X.X. Moreover, it is germane to literature, e.g. [37], in terms of PLAL technique producing nanoscaled polymorphs of titanium(IV) oxide.

Particles which appear as nearly perfect spheres show a very smooth surface and evenly distributed

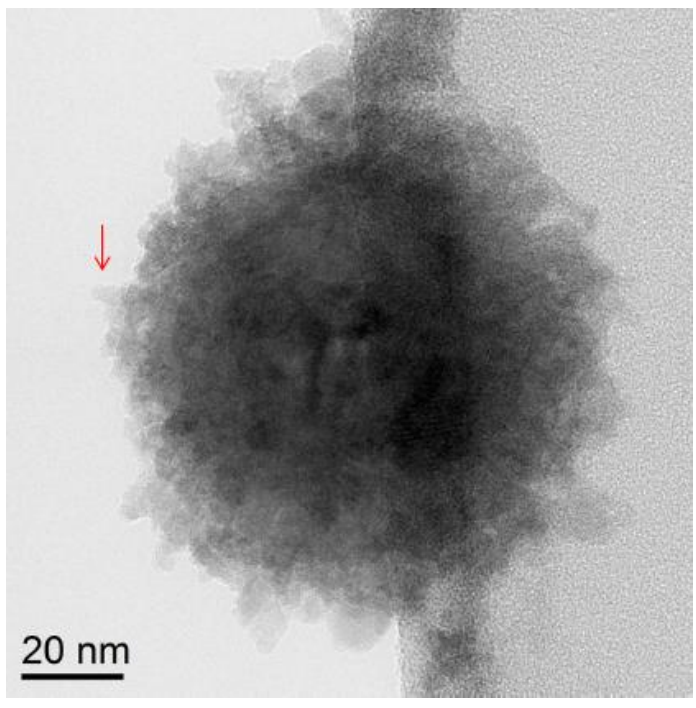

grey values. They are amorphous (see Fig. $7 \mathrm{~b}$ and h). In the fraction comprised by the small particles different states of crystallinity were detected. They are amorphous, crystalline or exist in an intermediate state; they can be seen in the gap between the two particles in Fig. $6 h$.

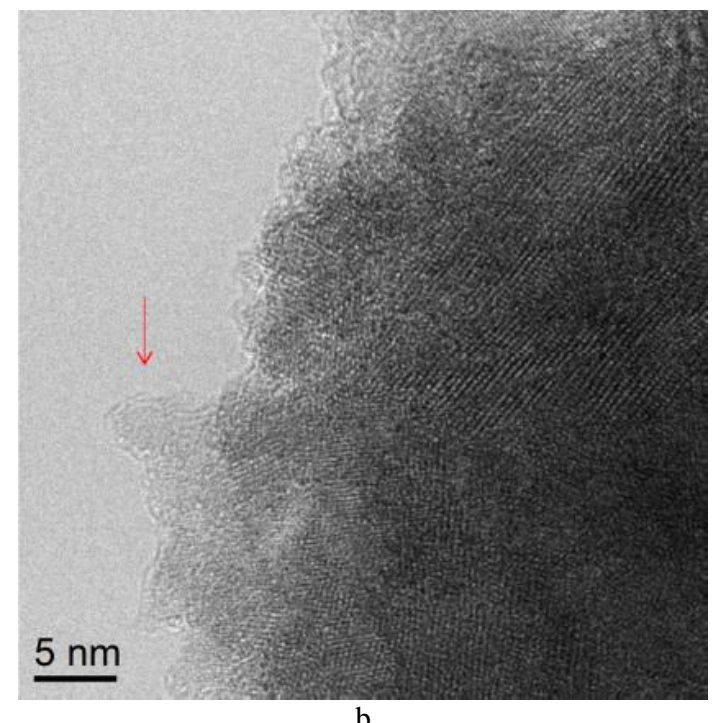

Fig. 9. a: Crystalline particle of the sample after $90 \mathrm{~min}$ laser ablation at the edge of grid film; b: HR-TEM image of the same particle with location indicated by red arrows and revealing that size of the small particles occupying the particle surface is smaller than the size of crystalline domains within the particle, which are visible by lattice planes.

\section{Conclusions}

Crystallinity and morphology of titanium dioxide nanoparticles obtained by pulsed laser ablation in liquid method and their polymorphs has been investigated in detail. Variety of $\mathrm{TiO}_{2}$ crystalline and amorphous phases have been detected with dominance of spherical anatase and rutile. Surface of spherical nanoparticles is smooth or buckled. Under certain ablation conditions rod-like nanoparticles were observed.

Crystallinity and morphology of nanoparticles depends on duration of laser ablation procedure. At longer ablation durations, concentration of anatase phase nanoparticles is higher and number of rodlike NPs increases.

NPs production rates were around $4.2 \mathrm{mg} \mathrm{h}^{-1}$, what is in accordance with literature at short ablation duration. Longer ablation duration leads to linear growth of NPs concentration, however, crystallinity and morphology of NPs depends strongly on ablation duration.

\section{Acknowledgments}

This work was supported by the SETNanoMetro Seventh Framework Programme project (project number 604577; call identifier FP7-NMP2013_LARGE-7).

\section{References}

[1] J. Fan, Z. Zhao, W. Liu, Y. Xue, S. Yin, Solvothermal synthesis of different phase $\mathrm{N}-\mathrm{TiO}_{2}$ and their kinetics, isotherm and thermodynamic studies on the adsorption of methyl orange, J. Colloid Interf. Sci. 470 (2016) 229-236.

[2] A.J. Antonczak, Ł. Skowronski, M. Trzcinski, V.V. Kinzhybalo, Ł.K. Łazarek, K.M. Abramski, Laserinduced oxidation of titanium substrate: Analysis of the physicochemical structure of the surface and sub-surface layers, Appl. Surf. Sci. 325 (2015) 217-226. 
[3] D.K. Pallotti, X. Ni, R. Fittipaldi, X. Wang, S. Lettieri, A. Vecchione, S. Amoruso, Laser ablation and deposition of titanium dioxide with ultrashort pulses at $527 \mathrm{~nm}$, Appl. Phys. B. 119 (2015) 445-452.

[4] M. Zimbone, M.A. Buccheri, G. Cacciato, R. Sanz, G. Rappazzo, S. Boninelli, R. Reitano, L. Romano, V. Privitera, M.G. Grimaldi, Photocatalytical and antibacterial activity of $\mathrm{TiO}_{2}$ nanoparticles obtained by laser ablation in water, Appl. Catal. B. 165 (2015) 487-494.

[5] R. Bargougui, N. Bouazizi. W. Ben Soltan, A. Gadri, A. Azzouz, S. Ammar, Controlled synthesis and electrical conduction properties of anatase $\mathrm{TiO}_{2}$ nanoparticles via the polyol method, Appl. Phys. A. 122 (2016) 309.

[6] R.S. Sabry, Y.K. Al-Haidarie, M.A. Kudhier, Synthesis and photocatalytic activity of $\mathrm{TiO}_{2}$ nanoparticles prepared by sol-gel method. J. SolGel Sci. Techn. 78 (2016), 299.

[7] M.V.Swapna, K.R. Haridas, An easier method of preparation of mesoporous anatase $\mathrm{TiO}_{2}$ nanoparticles via ultrasonic irradiation, J. Exp. Nanosci. 11 (2016) 540-549.

[8] JJ. Tao, M. Zhang, JG. Lv, SW. Shi, ZZ. Gong, G. Yao, YL. Cheng, G. He, XS. Chen, ZQ. Sun, Effects of Hydrothermal Time on the Morphologies of Rutile $\mathrm{TiO}_{2}$ Hierarchical Nanoarrays and Their Optical and Photocatalytic Properties, Sci. Adv. Mater. 8 (2016) 941-947.

[9] L, Yang, M, Gong, X, Jiang, D, Yin, X. Qin, B. Zhao, W. Ruan, Investigation on SERS of different phase structure $\mathrm{TiO}_{2}$ nanoparticles, J. Raman Spectrosc. 46 (2015) 287-292.

[10] M. Kobayashi, H. Kato, M. Kakihana, Synthesis of Titanium Dioxide Nanocrystals with Controlled Crystal- and Micro-structures from Titanium Complexes, Nanomater. Nanotechno. 3 (2013) 110.

[11] Y.F. Lin, K.L. Tung, Y.S. Tzeng, J.H. Chen, K.S. Chang, Evaluation of system reliability for a cloud computing system with imperfect nodes, J. Membr. Sci. 389 (2012) 83.

[12] H.J. Hong, S.K. Sarkar, B.T. Lee, Formation of $\mathrm{TiO}_{2}$ nano fibers on a micro-channeled $\mathrm{Al}_{2} \mathrm{O}_{3}-$ $\mathrm{ZrO}_{2} / \mathrm{TiO}_{2}$ porous composite membrane for photocatalytic filtration, J. Eur. Ceram. Soc. 32 (2012) 657.

[13] X.P. Cao, D. Li, W.H. Jing, W.H. Xing, Y.Q. Fan, Synthesis of visible-light responsive $\mathrm{C}, \mathrm{N}$ and $\mathrm{Ce}$ co-doped $\mathrm{TiO}_{2}$ mesoporous membranes via weak alkaline sol-gel process, J. Mater. Chem. 22 (2012) 15309.
[14] X. Wang, F. Shi, W. Huang, C. Fan, Synthesis of high quality $\mathrm{TiO}_{2}$ membranes on alumina supports and their photocatalytic activity, Thin Solid Films. 520 (2012) 2488.

[15] M. Lombardi, P. Palmero, M. Sangermano, A. Varesano, Electrospun polyamide-6 membranes containing titanium dioxide as photocatalyst, Polym Int. 60 (2011) 234-239.

[16] H.R. Pant, B. Pant, P. Pokharel, H.J. Kim, L.D. Tijing, C.H. Park, D.S. Lee, H.Y. Kim, C.S. Kim, Photocatalytic $\mathrm{TiO}_{2}-\mathrm{RGO} /$ nylon-6 spider-wavelike nano-nets via electrospinning and hydrothermal treatment, J. Membr. Sci. 429 (2013) 225-234.

[17] X. Ding, S. Zhou, L. Jiang, H. Yang, Preparation, photocatalytic activity and mechanism of nanoTitania/Nafion hybrid membrane, Sci. Tech. 58 (2011) 345 .

[18] M.H. Mahdieh, B. Fattahi, Size properties of colloidal nanoparticles produced by nanosecond pulsed laser ablation and studying the effects of liquid medium and laser fluence, Appl. Surf. Sci. 329 (2015) 47-57.

[19] S.I. Alnassar, E. Akman, B.G. Oztoprak, E. Kacar, O. Gundogdu, A. Khaleel, A.Demir, Study of the fragmentation phenomena of $\mathrm{TiO}_{2}$ nanoparticles produced by femtosecond laser ablation in aqueous media, Opt. Laser Technol. 51 (2013) 17-23.

[20] S.M. Hong, S. Lee, H.J. Jung, Y. Yu, J.H. Shin, Ki.Y. Kwon, M.Y Choi, Simple Preparation of Anatase $\mathrm{TiO}_{2}$ Nanoparticles via Pulsed Laser Ablation in Liquid, Bull. Korean Chem. Soc. 34 (2013) 279-282.

[21] M. Zimbone, G. Cacciato, M.A. Buccheri, R. Sanz, N. Piluso, R. Reitano, F.La Via, M.G. Grimaldi, V. Privitera, Photocatalytical activity of amorphous hydrogenated $\mathrm{TiO}_{2}$ obtained by pulsed laser ablation in liquid, Mat. Sci. Semicon. Proc. 42 (2016) 28-31.

[22] E.L. Papadopoulou, R. Intartaglia, A. Scarpellini, M. Rodio, I.S. Bayer, A. Athanassiou, Nanocomposite fabrication via direct ultra-fast laser ablation of titanium in aqueous monomer solution, Laser Phys. Lett. 12 (2015) 1-6.

[23] C.L Sajti, R. Sattari, B.N. Chichkov, S. Barcikowski, Gram Scale Synthesis of Pure Ceramic Nanoparticles by Laser Ablation in Liquid, J. Phys. Chem. C. 114 (2010) 2421-2427.

[24] C. Yang, Y. Tian, L. Cui, D. Zhang, Laser-induced changes in titanium by femtosecond, picosecond and millisecond laser ablation, Radiat. Eff. Defects Solids. 170 (2015) 528-540. 
[25] W. Perrie, A. Rushton, M. Gill, P. Fox, W. O’Neill, Femtosecond laser micro-structuring of alumina ceramic, Appl. Surf. Sci. 248 (2005) 213-217.

[26] D. Tan, G. Lin, Y. Liu, Y. Teng, Synthesis of nanocrystalline cubic zirconia using femtosecond laser ablation, J. Nanopart. Res. 13 (2011) 11831190.

[27] A. Hamad, L. Li, Z. Liu, A comparison of the characteristics of nanosecond, picosecond and femtosecond lasers generated $\mathrm{Ag}, \mathrm{TiO}_{2}$ and $\mathrm{Au}$ nanoparticles in deionized water, Appl. Phys. AMater. 120 (2015) 1247-1260.

[28] A.V. Simakin, V.V. Voronov, N.A. Kirichenko, G.A. Shafeev, Nanoparticles produces by laser ablation of solids in liquid environment, Appl. Phys. A-Mater. 79 (2004) 1127-1132.

[29] A. Schwenke, P. Wagener, S. Nolte, S. Barcikowski, Influence of processing time on nanoparticle generation during picosecond-pulsed fundamental and second harmonic laser ablation of metals in tetrahydrofuran, Appl. Phys. A-Mater. 104 (2004) 77-82.

[30] V.D. Hodoroaba, C. Motzkus, T. Macé, S. VaslinReimann, Performance of High-Resolution SEM/EDX Systems Equipped with Transmission Mode (TSEM) for Imaging and Measurement of Size and Size Distribution of Spherical Nanoparticles, Microsc. Microanal., 20 (2014) 602-612.

[31] S. Rades, V.D. Hodoroaba, T. Salge, T. Wirth, M. Pilar Lobera, R. Hanoi Labrador, K. Natte, T. Behnke, T. Gross, W.E.S. Unger, High-resolution imaging with SEM/T-SEM, EDX and SAM as a combined methodical approach for morphological and elemental analyses of single engineered nanoparticles, RSC Adv. 4 (2014) 49577-49587.
[32] V.D. Hodoroaba, S. Rades, W.E.S. Unger, Inspection of morphology and elemental imaging of single nanoparticles by high-resolution SEM/EDX in transmission mode, Surf. Interface Anal. 46 (2014) 945-948.

[33] C. Deiana, M. Minella, G. Tabacchi, V. Maurino, E. Fois and G. Martra, Shape-controlled $\mathrm{TiO}_{2}$ nanoparticles and $\mathrm{TiO}_{2} \mathrm{P} 25$ interacting with $\mathrm{CO}$ and $\mathrm{H}_{2} \mathrm{O}_{2}$ molecular probes: a synergic approach for surface structure recognition and physicochemical understanding, Phys. Chem. Chem. Phys. 15 (2013) 307-315.

[34] E. Ortel, L. Pellutiè, F. Pellegrino, V. Maurino, J. Mielke, B. Powierza, I. Häusler, W. Österle, V.D. Hodoroaba, Shape Recognition of Nanoparticles by High-Resolution SEM and TSEM. Microsc. Microanal. 21 (2015) 2401-2402.

[35] A. Chaturvedi, M.P. Joshi, P. Mondal, A.K. Sinha, A.K. Srivastava, Growth of anatase and rutile phase $\mathrm{TiO}_{2}$ nanoparticles using pulsed laser ablation in liquid: Influence of surfactant addition and ablation time variation. Appl. Surf. Sci. 396 (2017) 303309.

[36] L. Kotsedi, Z.Y. Nuru, S.M. Eaton, F.R. Cummings, S. Lo Turco, O.M. Ntwaeaborwa, R. Ramponi, M. Maaza, Titanium oxide nanocoating on a titanium thin film deposited on a glass substrate, Thin Solid Films. 603 (2016) 446451.

[37] M. Amin, J. Tomko, J.J. Naddeo, R. Jimenez, D.M. Bubb, M. Steiner, J. Fitz-Gerald, S.M. O'Malley. Laser-assisted synthesis of ultra-small anatase $\mathrm{TiO}_{2}$ nanoparticles. Appl. Surf. Sci. 348 (2015) 30-37. 


\section{Supplementary data}

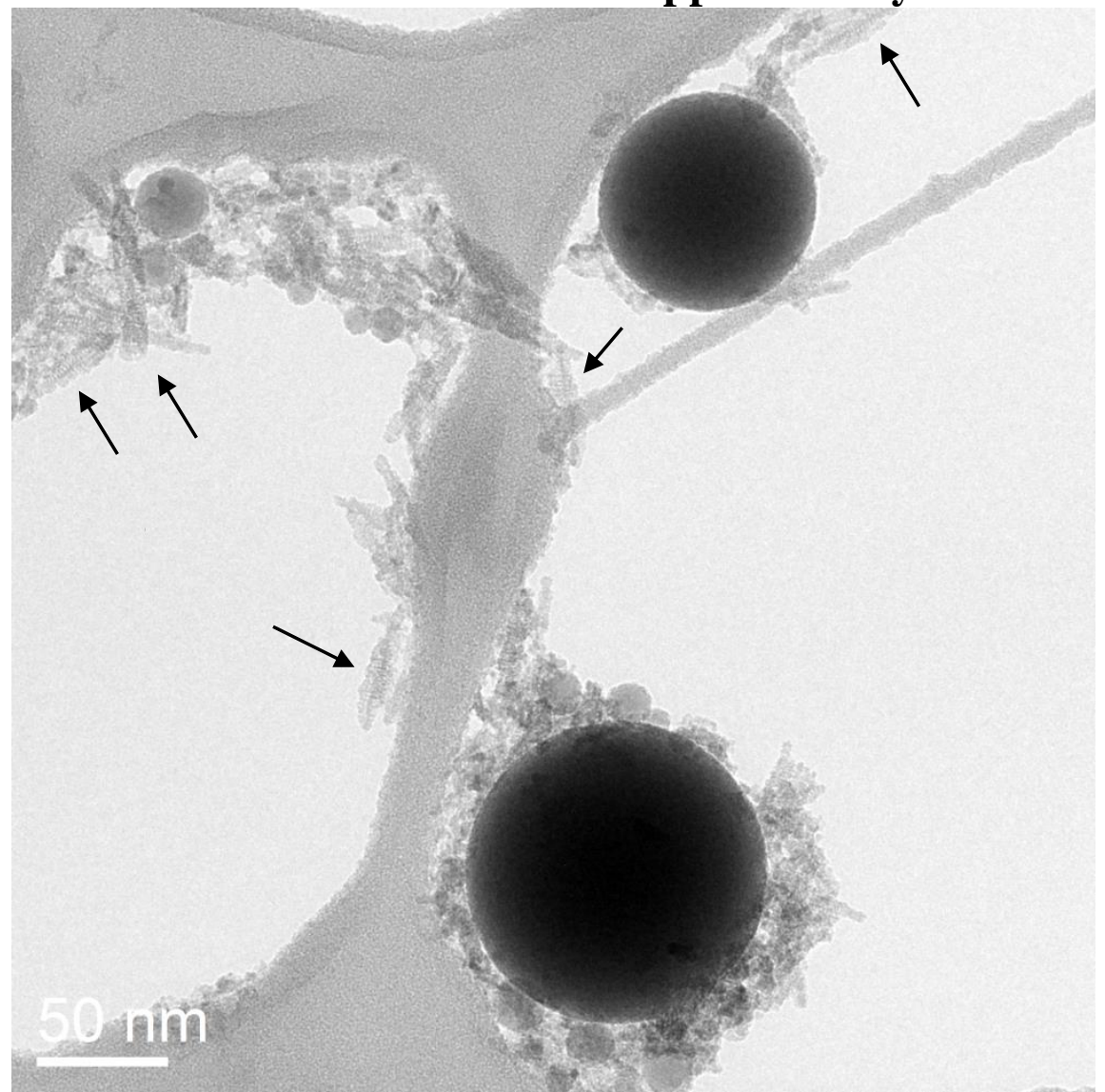

Fig. S1. HR-TEM image of 90min-sample revealing crystallinity of rod-type shaped particles (indicated by black arrows). 